Original Article - Clinical Science

\title{
Transnational review of visual standards for driving: how Australia compares with the rest of the world
}

\author{
Mabel K Yan MBBS(Hons), ${ }^{1,2}$ Himeesh Kumar MBBS(Hons), ${ }^{1,2}$ Nathan Kerr \\ FRANZCO, ${ }^{2,3}$ Felipe A Medeiros MD PhD, ${ }^{4}$ Sukhpal S Sandhu FRANZCO, ${ }^{2,3}$ J onathan \\ Crowston PhD FRANZCO 2,3,5 and Yu Xiang George Kong PhD FRANZCO ${ }^{2,3}$
}

1. The Alfred Hospital, Melbourne, Victoria, Australia.

2. Centre for Eye Research, Melbourne, Victoria, Australia.

3. Royal Victorian Eye and Ear Hospital, Victoria, Australia.

4. Department of Ophthalmology, Duke University, Durham, North Carolina, USA.

5. Centre for Vision Research, Duke-NUS, Singapore, Singapore.

Correspondence: Yu Xiang George Kong, Royal Victorian Eye and Ear Hospital, 32 Gisborne St, East Melbourne, VIC 3002, Australia george.kong@eyeandear.org.au

Short running title: Transnational review of driving visual standards Received 23 February 2019; accepted 18 May 2019 Funding sources / Financial disclosure: None Conflict of interest: None

This is the author manuscript accepted for publication and has undergone full peer review but has not been through the copyediting, typesetting, pagination and proofreading process, which may lead to differences between this version and the Version of Record. Please cite this article as doi: 10.1111/ceo.13572

This article is protected by copyright. All rights reserved. 


\section{ABSTRACT}

I mportance: Driving is a highly visual task and a primary mode of transportation for many people around the world.

Background: There appears to be little uniformity of vision standards across the world for driving. We reviewed the basic screening visual requirements for obtaining standard private and commercial driving licences for a total of 70 jurisdictions, and reviewed the evidence behind these standards.

Design: Systematic review of basic screening vision standards worldwide for driving and literature review.

Samples: Published online documentation on visual acuity and field requirements for driving.

Methods: Journal articles, government reports and websites obtained via a Google search were used to review the regulations for driving. This was limited by the comprehensiveness of resources, and countries were excluded if the requirements were unclear or unattainable. A literature review was performed using Medline with keywords vision, driving and visual field.

Main Outcome Measures: Visual parameters used for driving assessment. Results: The results suggest significant variations across the world. The visual acuity requirements for a private licence ranges from a minimum of $6 / 9$ to $6 / 60$. The minimum binocular horizontal field requirement ranges from $110^{\circ}$ to $150^{\circ}$. In general, standards for a commercial licence are stricter compared to a private 
licence. A literature review could not support the current driving standards as evidence-based.

Conclusions and Relevance: The disunity of driving vision requirements worldwide likely reflects the inconclusive evidence base. Accounting for individual differences and the ability to predict individual risk is important in the context of determining driving licensure.

Key Words: driving; vision; eye disease; vision standards; visual acuity

\section{I NTRODUCTI ON}

Driving is a highly visual task and a primary mode of transportation internationally. With the advent of ride-sharing technology becoming widespread around the globe, private drivers are increasingly acting as commercial drivers. The acceptance of international driving permits in over 130 countries worldwide gives motorists the ability to drive internationally without further tests if their domestic licence is valid. Consequently, there is a need for an international approach in understanding the visual standards for driving.

Currently, visual acuity and visual field tests form the foundation of many driver licencing screening assessments worldwide. Despite extensive research investigating the role of vision in driving, evidence to support these tests as accurate indicators of driver safety or performance is still lacking. Furthermore, previous studies examining the visual standards for driving across the United States of America (USA) and Europe report significant variation between jurisdictions. ${ }^{1,2}$ 
We compare the screening visual requirements for holding both private and commercial drivers' licence across the world, and examine the evidence behind these regulations.

\section{METHODS}

\subsection{A comparison of minimum screening visual requirements for a}

\section{standard licence}

The requirements for obtaining a driving licence were obtained via online Google searches. Information was gathered from available journal articles, government reports and websites (Table 1). Bibliographies from websites were also reviewed for further relevant information sources. Table 3 details our search method for each continent. J urisdictions were search individually using a combination of the jurisdiction's name with search terms including "driving", "minimum", "vision", "acuity", "visual field", "eyesight" or the country's licensing agency (e.g. "DVLA"). We aimed to obtain standards for countries worldwide so that there is representation from all continents. Our search was limited by the lack of resources available online and the results attainable in English using an English Google search. A total of 70 jurisdictions were included.

\subsection{The evidence base - literature search}

\subsubsection{Search Strategy and Information sources}

MEDLI NE was searched without publication year or publication status restrictions and limited to articles in English. Two separate searches were carried out by using the terms "visual field" and "automobile driving", and, "visual acuity" and "automobile driving". The reference lists of identified studies were also screened for potentially relevant papers. 


\subsubsection{Selection Criteria}

Randomised controlled trials, cohort studies, case-control studies and government reports were all considered for inclusion. Studies considered for review had the following characteristics: (i) drivers aged 18 years and older, (ii) participants with decreased visual acuity or visual field, (iii) driving performance as an outcome determined by driving simulator performance or an on-road driving assessment, or driving safety as an outcome, determined by motor vehicle crash rates.

\subsubsection{Data Collection and Analysis}

The titles and abstracts of retrieved results were screened to determine whether they met inclusion criteria. The full text of all potentially relevant studies were obtained and the results are narratively described.

\section{RESULTS}

\subsection{Comparison and summary of visual standards: private licences}

\subsubsection{Basic visual acuity requirements}

Visual acuity (VA) testing appears to be a universal basic screening requirement to hold a licence. There is some uniformity in VA standards worldwide, particularly in higher income countries. (See Table 4). A baseline binocular best corrected visual acuity (BCVA) of 6/12 or equivalent on the Snellen chart is required in Australia, the United Kingdom (UK) and the European Union (EU).

The majority of states in the USA require a minimum BCVA of 20/40 using both eyes. (See Table 5) New Jersey requires a slightly lower BCVA of 20/50, while Georgia and Kentucky require an even lower BCVA of 20/60. In Florida, applicants with 20/50 vision or worse in either eye, with or without correction, are referred to 
an ophthalmologist. If a minimum BCVA of $20 / 70$ in either eye can be achieved, a licence may be granted.

Functional vision assessment is also performed in some countries. In the UK, drivers must be able to read a car number plate from 20 meters in addition to a BCVA of $6 / 12$. The ability to read a number plate from 23 metres with or without correction alone, is used for licensure in Hong Kong.

\subsubsection{Basic visual field requirements}

The visual field (VF) standards to hold a licence vary significantly worldwide (See Tables 4 and 5). Some jurisdictions do not include VF requirements, while others have specific requirements for the horizontal and vertical field. In general, stricter laws govern the licensure in higher income compared to lower income countries.

\subsubsection{North America}

The basic VF requirements to hold a standard licence within the USA are highly variable (See Table 5). The majority of the states assess a binocular VF, and a minimum of $140^{\circ}$ in the horizontal meridian is a common standard. Some states also have minimum requirements for each eye. Kentucky is the only state that specifies conditions for the vertical field extent. In contrast, VF testing is not used in the basic assessment for licensure in California, Alaska, Delaware, Idaho and New Jersey.

\subsubsection{South America}

Similar to some nations in the Commonwealth and Asia, Colombia also has a minimum horizontal field standard of $120^{\circ}$.

\subsubsection{Commonwealth Countries}


Many Commonwealth countries including the UK, Singapore and Canada share a minimum VF requirement of $120^{\circ}$ in the horizontal meridian (See Table 4). VF testing is not required in Singapore unless the driver is monocular - defined as VA worse than 6/36 in one eye. In 2010, Australia revised its minimum horizontal requirement from $120^{\circ}$ to $110^{\circ}$ in order to accommodate for monocular drivers in obtaining a private licence. In addition, no defects are to be present within a radius of the central $20^{\circ}$. However, a scattered or single cluster of up to three contiguous spots within the central field is acceptable. This exception arose when an individual missing three contiguous points successfully argued in a legal case that his scotoma was no larger than that of the blind spot in a monocular driver.

\subsubsection{European Countries}

Countries within Europe currently have their own regulations, but there is a movement towards harmonisation. The EU minimum recommendation is $120^{\circ}$ along the horizontal field, at least $50^{\circ}$ left and right, and $20^{\circ}$ in the vertical meridian. Additionally, no defects are to be present within a radius of the central $20^{\circ}$.

\subsubsection{Asia}

The VF requirements differ substantially across Asia (See Table 4). Jurisdictions including China, Hong Kong and Malaysia do not assess VF routinely, while Taiwan requires a minimum horizontal field of $150^{\circ}$ - one of the highest standards in the world. Japan also requires a horizontal field of $150^{\circ}$, but in monocular drivers only. As similar with other Commonwealth nations, Philippines also requires a continuous $120^{\circ}$ minimum in the horizontal meridian.

\subsubsection{Africa}

Many countries in Africa, including Kenya and Nigeria, do not include VF tests as part of their screening for licensure. An exception is South Africa which has clear 
regulations that a minimum binocular horizontal field of $115^{\circ}$ is required if a monocular VF of $70^{\circ}$ temporally is not satisfied.

\subsubsection{The method of assessing the visual fields}

Most jurisdictions do not give specifications on the method of VF assessment. The Esterman visual field test (EVFT) is acceptable in Australia, UK and Canada. It is a binocular supra-threshold test with one-hundred and twenty points presented in the VF considered to be important for driving which is relatively fast to perform. In Australia, assessment by confrontation is adequate when there is no clinical suggestion of field impairment. If a defect is suspected, monocular automated static perimetry is an acceptable minimum baseline test, but an EVFT is required if there is a large field defect or if a progressive eye condition is present. The Australian guidelines strictly specify that the test must have a false positive score of less than 20 percent to be considered reliable. Some jurisdictions such as the UK and Canada also have guidelines that a white Goldmann III 4e target or equivalent should be used. (Tables 4 and 5 )

The lack of guidance provided around the specific tests which may be used to determine VF extents is likely reflective of the inconclusive nature of the underlying evidence. Despite acceptance of the EVFT, there is minimal evidence to support it as a valid tool to assess driving safety.

\subsubsection{Pattern of visual field loss}

Most jurisdictions do not specify a minimum distribution of the VF across the midline. Some states in the USA such as Kentucky, stipulate a minimum of $35^{\circ}$ to the left and right of fixation in the horizontal field. Similarly, the EU also requires at least $50^{\circ}$ to the left and right of the midline. Furthermore, central scotomas are an exclusion criterion in some jurisdictions. In Australia, New Zealand, Philippines, UK and the EU, 
a driver cannot hold a licence if they have any field defect within $20^{\circ}$ of fixation above or below the horizontal meridian.

\subsubsection{Important visual conditions}

A multitude of visual conditions can impact driving and few jurisdictions have clear regulations surrounding their restrictions. In Australia, individuals with diplopia cannot hold an unconditional licence if it affects fixation on objects within the central $20^{\circ}$ of the primary direction of gaze. However, they may be permitted to hold a conditional licence if other visual criteria are met and their condition is managed adequately with corrective lenses. Similar restrictions apply in the UK.

Progressive eye conditions such as glaucoma, optic neuropathy, cataract and retinitis pigmentosa have the potential to impair vision over time. The current Australian guidelines stipulate that the sole diagnosis of a progressive eye condition mandates an EVFT to ensure the VF criteria is fulfilled, and regular monitoring of their condition is required to maintain licensure. In addition, although not routinely tested, contrast sensitivity could also be a useful and important adjunct test. This would be relevant for driving in low-lighting environments, particularly for those with cataract or macular degeneration.

After a sudden loss of vision in an eye, a driver may still be able to meet local criteria for driving. In Australia, such drivers cannot drive for a period after the onset of their visual loss and should allow time re-establish stereopsis and adaptation to the condition.

\subsubsection{Conditional or restricted licences}

Some jurisdictions such as the UK, Australia, New Zealand and some American and Canadian states have conditional licences that allow motorists with progressive or long-term medical conditions to drive with restrictions and periodic review. For 
example, Australian drivers can be restricted to driving only in daylight hours, within a certain radius from home or only during off-peak hours.

\subsubsection{Bioptic telescope and driving}

Bioptic telescopes are not routinely permitted or readily available in Australia, but in some jurisdictions within the USA and Canada, they can be used to meet licensure standards. The device consists of telescopic lens that are mounted to regular spectacle frames. Subjects can selectively bring objects into magnified view whilst driving with small head-dipping movements. Studies demonstrate that bioptic telescopes can meet the needs of drivers with impaired central vision and are helpful aids for driving. ${ }^{3}$ However, despite their acceptance, there is limited evidence exploring its association with driving performance and MVC risk. Wood et al. conducted a study comparing 23 bioptic drivers with central vision loss with agedmatched controls ${ }^{4}$ and found bioptic drivers displayed poorer steering and lane position control. However, despite these differences, bioptic drivers displayed proficient on-road driving skills as evaluated by two back-seat assessors using a standardised scoring system.

\subsection{Comparison and summary of visual standards: commercial licence}

\subsubsection{Visual acuity}

A minimum VA of $6 / 9$ is a common requirement for commercial drivers in Canada, South Africa, Kenya, Nigeria, Australia and New Zealand. Many jurisdictions mandate a lowest uncorrected VA or limit the strength of correction required to obtain the minimum VA to drive.

Similar to private licence guidelines, many countries place restrictions on the minimum VA in a driver's weaker eye. (Table 6) Australian drivers require a BCVA of at least $6 / 12$ for private licensure. This is upgraded to an uncorrected minimum VA 
of 6/9 in the better eye and at least 6/18 in the worse eye for a commercial licence. (See Table 6) In the EU, a VA of 6/7.5 in better eye and no worse than $6 / 60$ in the weaker eye is required. This may be with correction, however, the means of correction may be no stronger than 8 dioptres in power.

\subsubsection{Visual field}

VF standards governing commercial drivers are more stringent compared to private vehicle drivers. In both the UK and EU, private drivers are required to have a minimum of $120^{\circ}$ in the horizontal field, compared to $160^{\circ}$ for commercial drivers. New Zealand has a common horizontal field requirement of $140^{\circ}$ for both private and commercial drivers. (Table 6)

As similar to private licence regulations, there is no unity of the standards worldwide. (See Table 6) The horizontal minimum standard is $160^{\circ}$ in the UK, compared to $150^{\circ}$ in Canada, $120^{\circ}$ in Singapore or, in Hong Kong it is not tested. Some jurisdictions further specify a minimum vertical extent of the field. A minimum of $20^{\circ}$ to $30^{\circ}$ continuous above and below fixation is a common standard. Some countries such as Australia have identical vertical field standards for both private and commercial vehicle drivers, despite increased horizontal field requirements for the latter group. Other jurisdictions such as EU and UK, have increased standards in both the horizontal and vertical meridians for commercial drivers.

The EVFT is the preferred method of assessment in the UK, Australia and Canada. This is compared to Kenya where having normal VFs as assessed by confrontational methods alone is acceptable. 
In the USA, only certified medical examiners listed on an online registry are permitted to perform physical qualification examinations for commercial drivers. Examiners need to complete periodic training and testing to maintain certification.

\section{DISCUSSION}

\subsection{The evidence base}

Since the late 1960s significant research has been conducted to determine the impact of visual function on driver safety and performance.

\subsubsection{Visual acuity}

Despite the large volume of literature available, a definitive consensus has not been reached regarding the impact of VA on driver safety or performance.

\subsubsection{Visual acuity and driving performance}

Schlag and colleagues compared an elderly group of drivers (aged 60-82 years) with a middle-aged group (aged 40-50 years) in a laboratory setting assessing driving. ${ }^{5}$ The authors found the elderly drivers who had decreased VA in comparison to the middle-aged subjects, performed worse. However, the elderly group showed no appreciable decrease in on-road driver performance. Higgins and Wood investigated the impact of simulated cataracts with optical blur in 24 normally-sighted subjects in a closed-road driving assessment study. ${ }^{6}$ The authors found that decreased acuity was associated with decreased sign recognition and hazard perception, but not with poorer driving performance. McGwin and colleagues examined the association between self-reported difficulty with driving tasks and various visual functions. ${ }^{7}$ They found that decreased VA was independently associated with driving difficulty in high-risk situations. 


\subsubsection{Visual acuity and motor vehicle crash risk}

Despite the ubiquity of VA assessments in driving licensure, there is a lack of evidence to support it as an accurate predictor of MVC risk. ${ }^{8-10}$ Many studies demonstrate a poor association between low VA and MVC rates. ${ }^{8,10-14} \mathrm{~A}$ study by Hills and Burg involving 14000 young and middle-aged drivers found no direct relationship between poor VA and high MVC rates. ${ }^{14}$ Similarly, Gresset and Meyer's case-control study with 1400 cases who had a MVC during their $70^{\text {th }}$ year were compared with 2636 controls who were not involved in a MVC. ${ }^{8}$ The authors found that having minimal VA alone, defined as equal to $6 / 12$ or $6 / 15$, did not correlate with a greater risk of MVCs. Likewise, Rubin and colleagues conducted a large epidemiological study examining 1801 drivers and found that poor VA was not associated with MVC rates. ${ }^{10}$

Few studies have demonstrated a positive correlation between reduced VA and MVCs. ${ }^{15-17}$ For example, a cohort study involving 125 drivers found that those with a VA worse than 20/40 were more likely to have a history of adverse events, but the differences were not statistically significant $(P=0.265) .{ }^{17}$

Confounders in the literature appear to cloud the association between VA and driver safety. There is evidence that those with impaired VA will self-restrict their driving and avoid challenging conditions such as peak hour or night time. ${ }^{13,18}$ Similarly, those individuals who do not meet the VA standards are prohibited from driving, which artificially decreases the MVCs associated with poor VA. Therefore, it is difficult to canvas the true association between these two variables. 


\subsubsection{Visual field}

It is intuitive that an adequate VF is essential for driving, however, defining a 'minimum' field for driving is not straightforward. Many studies have addressed the relationship between VF loss and driving.

\subsubsection{Visual field and simulation studies}

Wood and colleagues conducted a series of experiments exploring the driving performance of elderly drivers on closed-road circuits when their VF was artificially reduced to a horizontal extent of $90^{\circ}$. They found that such simulated VF restrictions were associated with impaired driving performance - with subjects driving more slowly and having longer reaction times. ${ }^{19,} 20$

Driving simulators have also been used to assess the role of vision in driving. Szlyk and colleagues found a greater proportion of subjects with VF defects due to retinitis pigmentosa (RP) had accidents in a driving simulator. ${ }^{21}$ In another study examining glaucoma patients with mild to moderate VF loss, Szlyk and colleagues found no increase in real-world or simulator accident rates compared to controls. ${ }^{22}$ However, in a subsequent study, glaucoma patients with a greater degree of VF loss were included, and an increased risk of simulator accidents was observed relative to controls. $^{23}$

\subsubsection{Visual field and motor vehicle crashes}

In one of the earliest studies exploring the relationship between VF loss and MVC risk, J ohnson and Keltner examined 20,000 eyes. ${ }^{24}$ They found that drivers with significant binocular field loss had double the rate of MVCs and traffic convictions compared to those without such field loss. Numerous other studies have also reported that VF loss is a risk factor for MVC. ${ }^{10,25-28}$ In particular, defects of different sub-regions of the field may have varying impacts on MVC rates. In a cohort study 
of 1801 drivers, Rubin and colleagues found that lower peripheral field loss was most important for predicting future crash involvement. ${ }^{10}$ Similarly, Huisingh and colleagues' retrospective cohort study of 2000 drivers reported that older drivers with severe impairment in the lower or left region of the driving VF - the field of vision used while driving - were more likely to have a history of at-fault MVC. ${ }^{26}$ In a subsequent study focusing only on glaucoma patients, Kwon and colleagues reported that VF impairment was independently associated with at-fault MVC involvement. ${ }^{27}$ More specifically, left VF defects showed the highest risk of MVC (RR $=3.16 ; \mathrm{P}=0.001$ ). However, as noted by Huisingh and colleagues, these studies were conducted in the USA, where left VF impairments may increase MVC vulnerability since vehicles are driven on the right side of the road. ${ }^{26}$ It is yet to be determined whether right VF defects affect MVC rates in countries where vehicles are driven on the left side of the road.

In contrast, some studies do not report a clear association between VF defects alone and increased MVC risk. ${ }^{29-32}$ In a study assessing the driving performance of 42 patients with RP and 87 control subjects, Fishman and colleagues could not find a significant correlation between VF loss and MVC rates. ${ }^{30}$ In a retrospective cohort study of 12,400 drivers conducted by Decina and colleagues and a case-control study by Owsley and colleagues involving 294 drivers, both authors could not find a link between VF loss and increased crash involvement. ${ }^{29}, 31$ Furthermore, Yuki and colleagues also reported no relationship between central binocular VF damage and MVC rates in a study investigating the association between point-wise VF sensitivities and MVC history in 247 patients with primary open-angle glaucoma. ${ }^{32}$

\subsection{I mportant Factors Affecting Driving Ability - Age and Cognition}

Driving is a heavily visual task but the ability to see clearly alone is not sufficient. Safe driving requires the ability to visualise objects clearly, recognise hazards, and 
react in a timely fashion to unexpected circumstances. Functions which inevitability decline with age such as physical health and cognition, are important to operate a vehicle.

Studies have demonstrated that visual attention and cognitive functions involving the ability to select, search and switch, have a key role in driving risk among older drivers. ${ }^{33}$ On-road driving assessments have found that people with dementia or mild cognitive impairment demonstrate poorer driving performance compared to controls and have higher rates of reported MVCs. ${ }^{34-37}$ However, a diagnosis of dementia alone should not result in driving prohibition, as accumulating evidence demonstrates that some people with mild dementia can display adequate driving fitness. ${ }^{38,} 39$ It is with progression of the disease that most patients with dementia will eventually have to cease driving, which is usually within 3 years of diagnosis. ${ }^{40}$

Advancing age also appears to have a negative impact on driving safety. In the USA, Lombardi et al analysed pooled data from a census of fatal traffic crashes from 2011 - 2014. ${ }^{41}$. During this time period, 120,809 fatal accidents were reported. After adjusting for age, the authors found the highest annual fatal intersection crash rate per 100,000 licensed drivers was for drivers aged 85 or older. Similarly, a study of 3425 drivers who underwent a formal driving evaluation found that the oldest-old (aged 85 years and older) reported more MVCs compared to the middle-aged (OR = $2.79,95 \% \mathrm{Cl} 1.88$ - 4.12) and were more likely to be considered unfit to drive by the official driving evaluation centre. ${ }^{42}$

Driving is a complex task and vision as an isolated predictor of driving performance or safety is not sufficient. Further research to develop a more predictive model for driving which combines all important factors including cognition and age is needed. 


\subsection{I mportance of individualised assessment}

The current literature suggests that severe VF impairments are associated with an increased risk of MVC, however, the impact of mild to moderate field loss is less clear. Studies have shown that individuals with long-standing lesions can develop effective adaptive strategies over time. ${ }^{43-47}$ They can compensate for their visual loss through improvements in eye and head movements, scanning in the affected field, and by more frequent saccades towards into the blind side and therefore an expansion of the seeing hemi-field. Results from more and more studies suggest that individual differences in visual compensation exist between drivers. ${ }^{48-50}$ Racette and Casson conducted a retrospective study exploring the impact of VF loss on driving performance and found that some patients who did not satisfy VF standards in many jurisdictions, could obtain "safe" driving outcomes when assessed by an occupational therapist. ${ }^{49}$ Similarly, Wood and colleagues also reported that some drivers with hemianopia or quadrantanopia were fit to drive compared with agematched controls. ${ }^{50}$ In another study investigating the on-road driving performance of patients with glaucoma, Haymes and colleagues found that despite fulfilling local driving licensure vision requirements, some patients with slight VF impairments were 6 times more likely to have a driving instructor intervene for reasons suggesting difficulty detecting peripheral obstacles and hazards. ${ }^{51}$ Variability of VF loss compensation exists between individuals.

Furthermore, it is also important to consider that standard automated perimetry (SAP) may not be a reliable tool to assess the impact of peripheral VF loss on driving ability. As a static white-on-white test performed in a controlled environment, SAP does not accurately reflect the demands that a complex task such as driving imposes on vision. Driving requires detection of stimuli in cluttered environments, division of attention and simultaneous use of both peripheral and central vision. Mounting evidence demonstrates that tests of the functional field of view may be more reliable 
predictors of MVC risk. This includes the useful field of vision (UFOV) test which assesses the total VF area in which useful information can be acquired without eye and head movements. ${ }^{52}$ Since its introduction, the UFOV test has been shown to be strongly associated with crash involvement. ${ }^{11,53}$ Owsley and colleagues found in a case-control study that drivers involved in non-injurious crashes were 5.5 times more likely to have a substantial UFOV impairment, ${ }^{31}$ while Rubin and colleagues reported that drivers with a reduced extent of the UFOV were 2.12 times more likely to crash than those with no loss of UFOV. ${ }^{10}$ Further, Wood and colleagues found that the selective attention subtest of the UFOV had the strongest predictive value of overall driving performance as assessed in a closed-road circuit in the presence of distracters. ${ }^{54}$ However, the UFOV is not readily available in Australia and often only used as an additional test for some patients.

In practice, the ability to predict individual risk is particularly important in the context of driving licensure. The decision to revoke an individual's licence needs to be well-justified. Current evidence from population-based studies suggest an increased-odds of MVC in those with significant VF loss, and UFOV tests appear to be an accurate predictor of MVC risk. ${ }^{10,24}$ However, individual risk prediction cannot be determined through findings from general epidemiological studies. Gracitelli and colleagues conducted a small prospective observational cohort study addressing this issue involving 117 drivers with glaucoma. ${ }^{55}$ The authors found that longitudinal divided attention metrics on the UFOV were significantly predictive of individual risk of MVC. Further prospective studies evaluating the prediction of individual risk with larger sample sizes are warranted.

The evidence suggests individual differences are important to account for in the assessment of driving fitness. This raises questions about the fairness of current regulations which may categorically deny licensure to those with particular field 
defects. The unique way in which each individual can compensate for their visual loss while driving is important to consider. In addition, vision is necessary but not sufficient for safe driving. The consideration of factors including cognition and age are also important. This is especially relevant when considering driving licensure, where our ability to predict future individual risk is of primary importance.

\subsection{Concluding Remarks}

Across the world, policy surrounding driving regulations inevitably presents an inherent challenge as the intrinsic desire for individual autonomy and independence is pitted against the need for community safety and risk minimisation. This study is the first large scale review of the basic screening visual requirements for driving across the world. It highlights a lack of unity in the standard for VA and VF for both private and commercial vehicles. Such disunity likely reflects the inconclusive nature of the underlying evidence, as well as the different socioeconomic conditions of different countries. Moreover, with little guiding evidence, a value judgement upon the relative priorities of individual autonomy and public safety needs to be made. Such judgements are likely to be influenced by local factors affecting each jurisdiction, and further account for the disunity observed. Further research is warranted to identify the role of an internationally-consistent minimum visual standard, and also evaluate the role of individualised assessments and risk prediction in driver licensing. 


\section{REFERENCES}

1. Bron $\mathrm{AM}$, Viswanathan $\mathrm{AC}$, Thelen $\mathrm{U}$ et al. International vision requirements for driver licensing and disability pensions: using a milestone approach in characterization of progressive eye disease. Clin Ophthalmo/ 2010;4:1361-9.

2. Casson EJ, Racette L. Vision standards for driving in Canada and the United States. A review for the Canadian Ophthalmological Society. Can J Ophthalmo/ 2000;35:192-203.

3. Bowers AR, Apfelbaum DH, Peli E. Bioptic telescopes meet the needs of drivers with moderate visual acuity loss. Invest Ophthalmol Vis Sci 2005; 46: 66-74.

4. Wood J M, McGwin G , Elgin J, Searcey K, Owsley C. Characteristics of on-road driving performance of persons with central vision loss who use bioptic telescopes. Invest Ophthalmo/ Vis Sci 2013;54:3790-7

5. Schlag B. Elderly drivers in Germany - Fitness and driving behavior. Accid Anal Prev 1993; 25:47-55.

6. Higgins KE, Wood JM. Predicting components of closed road driving performance from vision tests. Optom Vis Sci 2005; 82:647-56.

7. McGwin G, Chapman V, Owsley C. Visual risk factors for driving difficulty among older drivers. Accid Anal Prev 2000;32: 735-44.

8. Gresset J A, Meyer FM. Risk of accidents among elderly car drivers with visual acuity equal to $6 / 12$ or $6 / 15$ and lack of binocular vision. Ophthalmic and Physiol Opt 1994; 14:33-7.

9. Owsley C, McGwin G. Vision and driving. Vision Res 2010;50:2348-61.

10. Rubin GS, Ng ESW, Bandeen-Roche K, Keyl PM, Freeman EE, West SK. A Prospective, Population-Based Study of the Role of Visual Impairment in Motor Vehicle Crashes among Older Drivers: The SEE Study. Invest Ophthalmol Vis Sci 2007;48:1483-91 
11. Ball K, Owsley C, Sloane ME, Roenker DL, Bruni J R. Visual attention problems as a predictor of vehicle crashes in older drivers. Invest Ophthalmol Vis Sci 1993; 34: 3110-23.

12. Fonda G. Legal blindness can be compatible with safe driving. Ophthalmology 1989; 96: 1457-9.

13. Keeffe JE. Vision impairment and older drivers: who's driving? $\mathrm{Br}$ J Ophthalmol2002; 86:1118-2.

14. Hills BL, Burg A. A reanalysis of California driver vision data: general findings. Report No. LR 768. Transport and Road Research Laboratories 1977. Crowthorne, Berkshire.

15. Hofstetter HW. Visual acuity and highway accidents. J Am Optom Assoc 1976; 47:887-93.

16. Humphriss D. Three South African studies on the relation between road accidents and drivers' vision. Ophthal Physiol Opt 1987; 7: 73-9.

17. Marottoli RA, Richardson ED, Stowe MH et al. Development of a test battery to identify older drivers at risk for self-reported adverse driving events. J $\mathrm{Am}$ Geriatr Soc 1998;46:562-8.

18. Freeman EE, Muñoz B, Turano KA, West SK. Measures of Visual Function and Time to Driving Cessation in Older Adults. Optom Vis Sci 2005; 82: 765-73.

19. Wood J M, Troutbeck R. Effect of restriction of the binocular visual field on driving performance. Ophthalmic Physiol Opt 1992; 12:291-8.

20. Wood J M, Troutbeck R. Elderly Drivers and Simulated Visual Impairment. Opt Vis Sci 1995; 72: 115-24.

21. Szlyk JP, Alexander KR, Severing K, Fishman GA. Assessment of driving performance in patients with retinitis pigmentosa. Arch Ophthalmol 1992; 110: 1709- 13. 
22. Szlyk JP, Taglia DP, Paliga J, Edward DP, Wilensky JT. Driving performance in patients with mild to moderate glaucomatous clinical vision changes. J Rehabil Res Dev 2002;39:467-82.

23. Szlyk JP, Mahler CL, Seiple W, Edward DP, Wilensky JT. Driving Performance of Glaucoma Patients Correlates With Peripheral Visual Field Loss. J Glaucoma 2005; 14: 145-50.

24. J ohnson CA, Keltner J L. Incidence of visual field loss in 20,000 eyes and its relationship to driving performance. Arch Ophthalmo/ 1983; 101:371-5.

25. Haymes SA, Leblanc RP, Nicolela MT, Chiasson LA, Chauhan BC. Risk of falls and motor vehicle collisions in glaucoma. Invest Ophthalmol Vis Sci 2007; 48: 1149-55.

26. Huisingh C, McGwin G, Wood J, Owsley C. The driving visual field and a history of motor vehicle collision involvement in older drivers: a populationbased examination. Invest Ophthalmol Vis Sci2015;56:132-8.

27. Kwon M, Huisingh C, Rhodes LA, McGwin G, Wood J M, Owsley C. Association between Glaucoma and At-fault Motor Vehicle Collision Involvement among Older Drivers: A Population-based Study. Ophthalmology 2016; 123:109-16.

28. McGwin G, Xie A, Mays A et al. Visual field defects and the risk of motor vehicle collisions among patients with glaucoma. Invest Ophthalmol Vis Sci 2005; 46: 4437-41.

29. Decina LE, Staplin L. Retrospective evaluation of alternative vision screening criteria for older and younger drivers. Accid Anal Prev 1993; 25:267-75.

30. Fishman GA, Anderson RJ, Stinson L, Haque A. Driving performance of retinitis pigmentosa patients. BrJ Ophthalmo/ 1981;65:122-6.

31. Owsley C, McGwin G, Ball K. Vision impairment, eye disease, and injurious motor vehicle crashes in the elderly. Ophthalmic Epidemio/ 1998;5:101-13. 
32. Yuki K, Asaoka R, Tsubota K. The relationship between central visual field damage and motor vehicle collisions in primary open-angle glaucoma patients. PLOS ONE 2014; 9 el15572

33. Richardson ED, Marottoli RA. Visual attention and driving behaviors among community-living older persons. J Gerontol A Biol Sci Med Sci 2003; 58:832-6

34. Chee J N, Rapoport MJ , Molnar F et al. Update on the Risk of Motor Vehicle Collision or Driving Impairment with Dementia: A Collaborative International Systematic Review and Meta-Analysis. AmJ Geriatr Psychiatry 2017; 25: 1376-90.

35. Dawson J D, Anderson SW, Uc EY, Dastrup E, Rizzo M. Predictors of driving safety in early Alzheimer disease. Neurology 2009; 72:521-7.

36. Grace J , Amick MM, D'Abreu A, Festa EK, Heindel WC, Ott BR. Neuropsychological deficits associated with driving performance in Parkinson“s and Alzheimer's disease. J Int Neuropsychol Soc 2005; 11: 76675.

37. Uc EY, Rizzo M, Anderson SW, Shi Q, Dawson JD. Driver route-following and safety errors in early Alzheimer disease. Neurology 2004;63:832-7.

38. Duchek J M, Carr DB, Hunt L et al. Longitudinal driving performance in earlystage dementia of the Alzheimer type. J Am Geriatr Soc 2003;51:1342-7.

39. Ott BR, Heindel WC, Papandonatos GD et al. A longitudinal study of drivers with Alzheimer disease. Neurology 2008; 70:1171-8.

40. Brown LB, Ott BR. Driving and Dementia: A Review of the Literature. / Geriatr Psychiatry Neurol 2004; 17:232-40.

41. Lombardi DA, Horrey WJ, Courtney TK. Age-related differences in fatal intersection crashes in the United States. Accid Anal Prev 2017;99:20-9.

42. Moon S, Ranchet M, Akinwuntan AE et al. The Impact of Advanced Age on Driving Safety in Adults with Medical Conditions. Gerontology 2018;64:291-9. 
43. Pambakian ALM, Wooding DS, Patel N, et al. Scanning the visual world: a study of patients with homonymous hemianopia. / Neurol Neurosurg Psychiatry.2000;69:751-759

44. Pambakian AL, Mannan SK, Hodgson TL, Kennard C. Saccadic visual search training: a treatment for patients with homonymous hemianopia. / Neurol Neurosurg Psychiatry. 2004; 75: 1443-1448.

45. Machner B, Sprenger A, Sander T et al. Visual search disorders in acute and chronic homonymous hemianopia: lesion effects and adaptive strategies. Ann NY Acad Sci. 2009; 1164:419-26.

46. Roth T, Sokolov AN, Messias A, Roth P, Weller M, Trauzettel-Klosinski S. Comparing explorative saccade and flicker training in hemianopia. Neurology. 2009; 72:324-331.

47. Kasneci E, Sippel K, Heister M et al. Homonymous Visual Field Loss and Its Impact on Visual Exploration: A Supermarket Study. Trans/ Vis Sci Technol. 2014;3:2.

48. Wood J M, McGwin G, Elgin J et al. Hemianopic and quadrantanopic field loss, eye and head movements, and driving. Invest Ophthalmol Vis Sci 2011;52:1220-5.

49. Racette L, Casson EJ. The impact of visual field loss on driving performance: evidence from on-road driving assessments. Optom Vis Sci 2005; 82:668-74.

50. Wood J M, McGwin G, Elgin J et al. On-road driving performance by persons with hemianopia and quadrantanopia. Invest Ophthalmol Vis Sci 2009; 50:577-85.

51. Haymes SA, Leblanc RP, Nicolela MT, Chiasson LA, Chauhan BC. Glaucoma and on-road driving performance. Invest Ophthalmol Vis Sci 2008;49:303541.

52. Ball K, Owsley C. The useful field of view test: a new technique for evaluating age-related declines in visual function. J Am Optom Assoc 1993; 64: 71-9. 
53. Owsley C, Ball K, Gerald McGwin J et al. Visual Processing Impairment and Risk of Motor Vehicle Crash Among Older Adults. JAMA 1998;279: 1083-8. 54. Wood J M, Chaparro A, Lacherez P, Hickson L. Useful field of view predicts driving in the presence of distracters. Optom Vis Sci 2012; 89:373-81.

55. Gracitelli CPB, Tatham AJ, Boer ER et al. Predicting Risk of Motor Vehicle Collisions in Patients with Glaucoma: A Longitudinal Study. PLOS ONE 2015; 10: e0138288 


\section{TABLES}

Table 1: Sources of information - jurisdictions worldwide

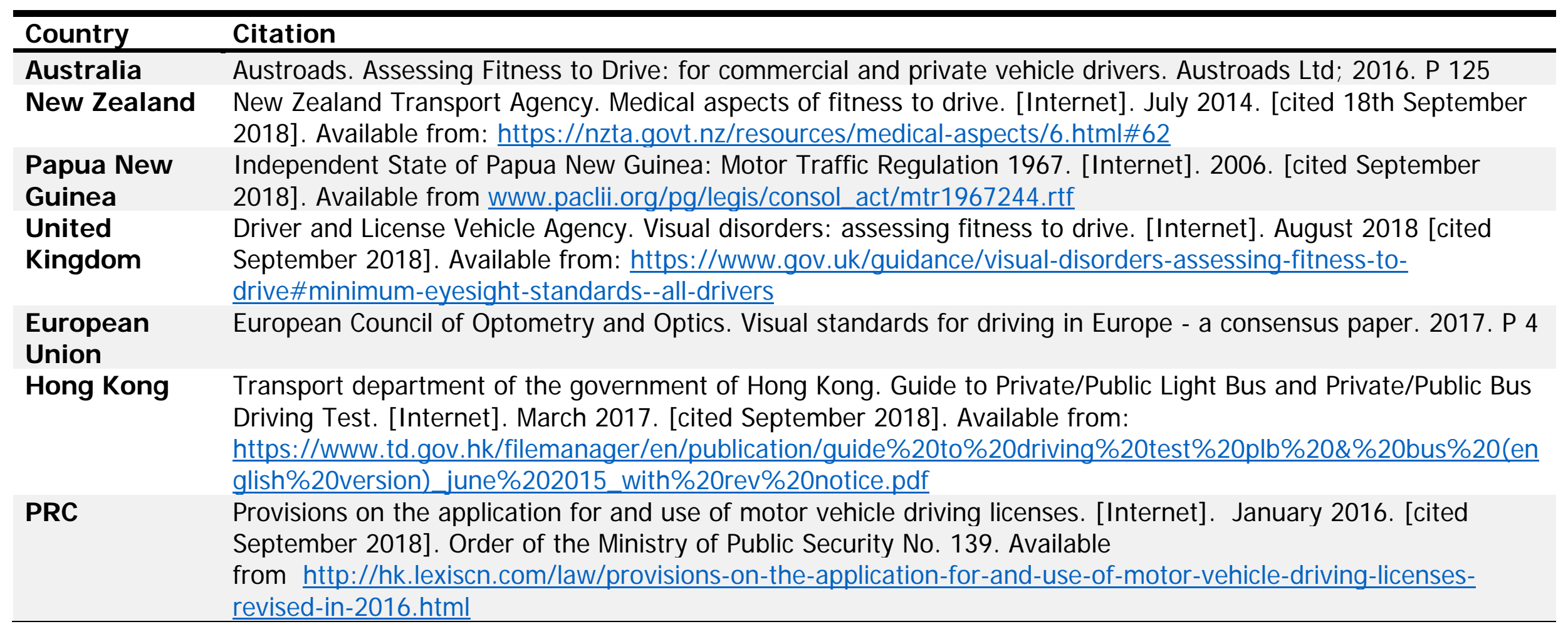

This article is protected by copyright. All rights reserved. 


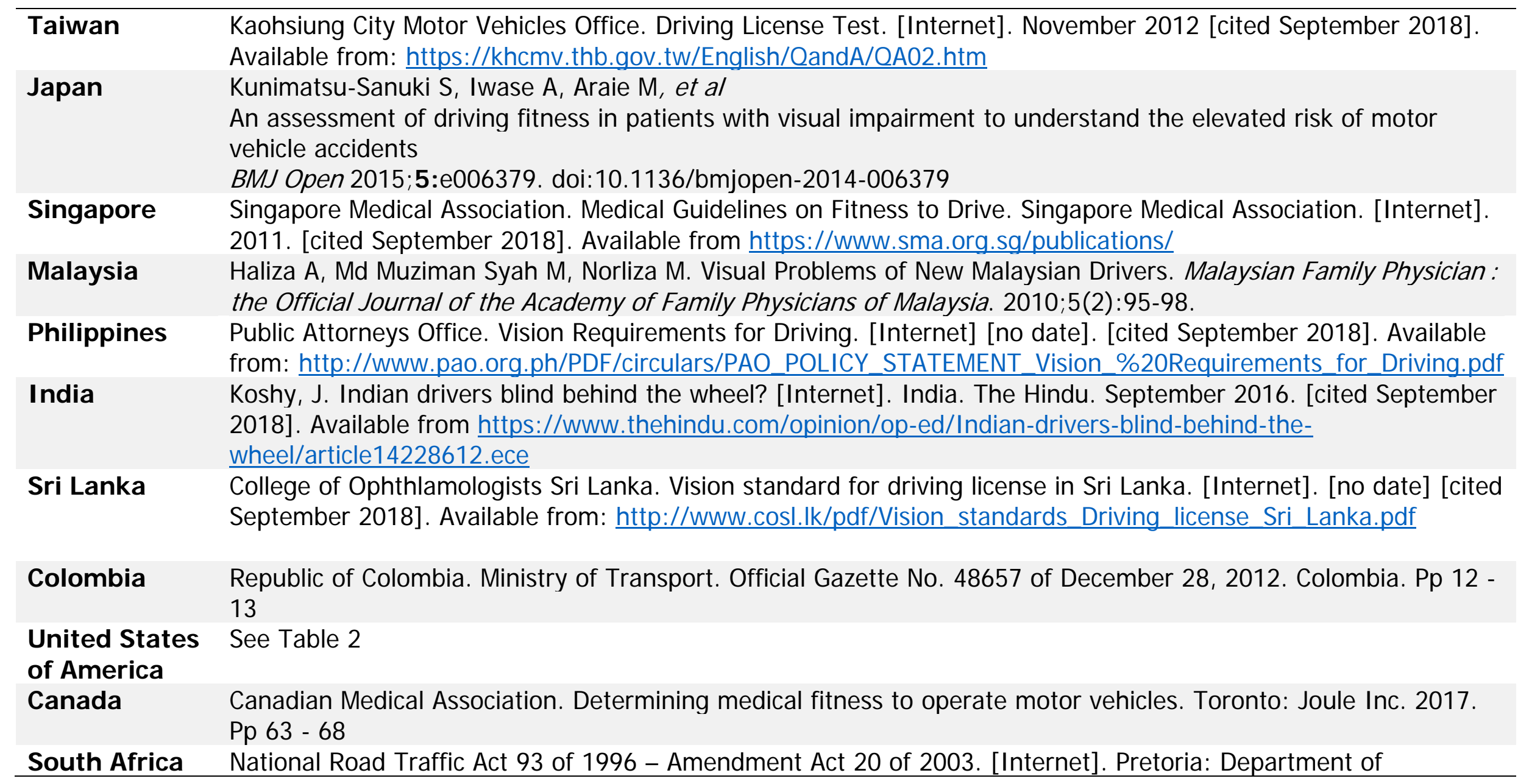

This article is protected by copyright. All rights reserved. 
Transport. 2003 [cited September 2018]. Available from: http://www. oasa.org.za/Regulation102.php

Kenya Gichangi MM, Gathecha GK, Kibogong D. Vision testing to prevent road traffic accidents in Kenya. Community Eye Health. 2015;28(91):S04-S06.

Nigeria N National Road Traffic Regulations. 79. Lagos Nigeria: The Federal Government press; 2004. pp. B 173-B 303. 
Table 2: Sources of information - United States of America

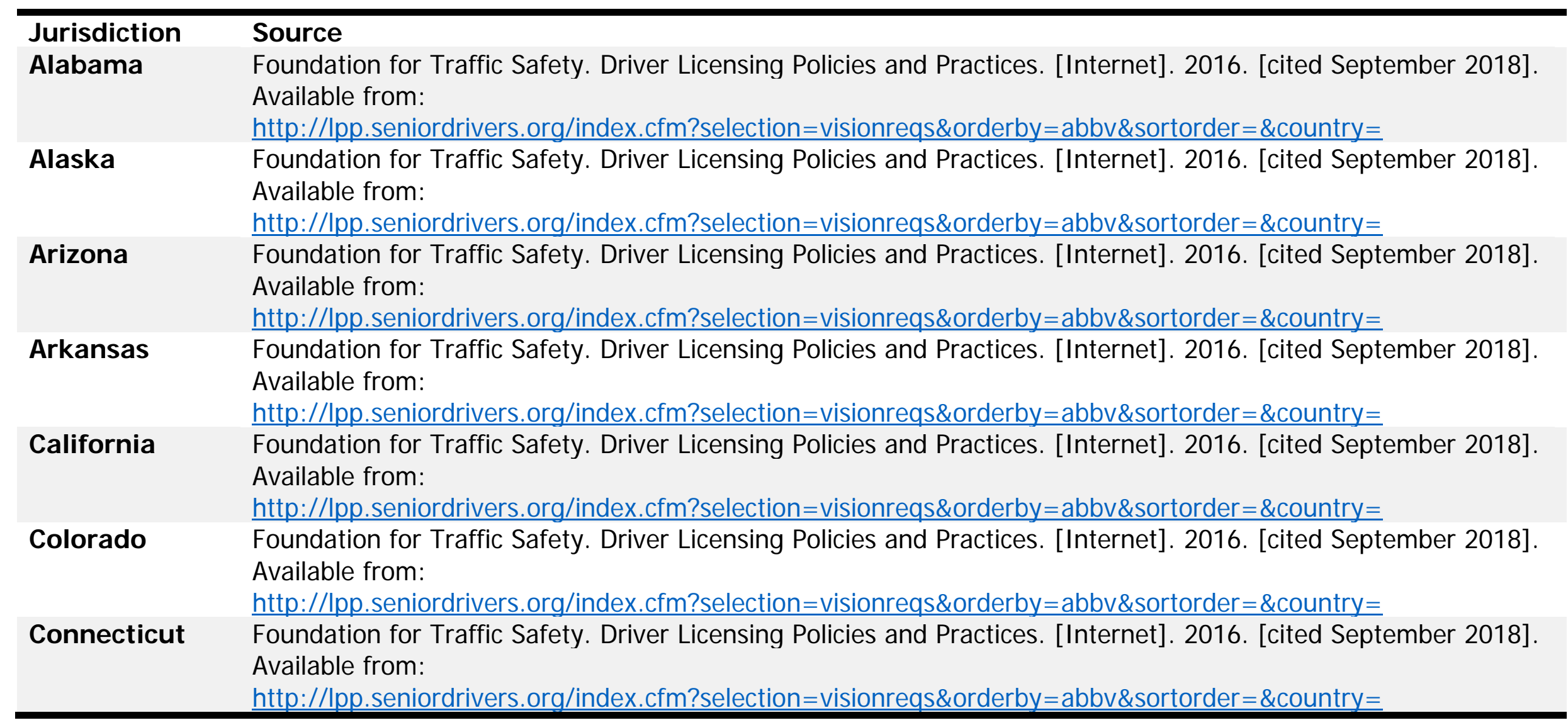

This article is protected by copyright. All rights reserved. 


\begin{tabular}{|c|c|}
\hline Delaware & $\begin{array}{l}\text { Foundation for Traffic Safety. Driver Licensing Policies and Practices. [Internet]. 2016. [cited September 2018]. } \\
\text { Available from: } \\
\text { http://lpp.seniordrivers.org/index.cfm?selection=visionreqs\&orderby=abbv\&sortorder=\&country= }\end{array}$ \\
\hline $\begin{array}{l}\text { District of } \\
\text { Columbia }\end{array}$ & $\begin{array}{l}\text { Department of Motor Vehicles. District of Columbia. [Internet]. [no date]. Available from } \\
\text { https://dmv. dc.gov/service/screening-vision }\end{array}$ \\
\hline Florida & $\begin{array}{l}\text { Foundation for Traffic Safety. Driver Licensing Policies and Practices. [Internet]. 2016. [cited September 2018]. } \\
\text { Available from: } \\
\text { http://lpp.seniordrivers.org/index. cfm?selection=visionregs\&orderby=abbv\&sortorder=\&country= }\end{array}$ \\
\hline Georgia & $\begin{array}{l}\text { Foundation for Traffic Safety. Driver Licensing Policies and Practices. [Internet]. 2016. [cited September 2018]. } \\
\text { Available from: } \\
\text { http://lpp.seniordrivers.org/index.cfm?selection=visionregs\&orderby=abbv\&sortorder=\&country= }\end{array}$ \\
\hline Hawaii & $\begin{array}{l}\text { Foundation for Traffic Safety. Driver Licensing Policies and Practices. [Internet]. 2016. [cited September 2018]. } \\
\text { Available from: } \\
\text { http://lpp.seniordrivers.org/index.cfm?selection=visionregs\&orderby=abbv\&sortorder=\&country= }\end{array}$ \\
\hline I daho & $\begin{array}{l}\text { Foundation for Traffic Safety. Driver Licensing Policies and Practices. [Internet]. 2016. [cited September 2018]. } \\
\text { Available from: } \\
\text { http://lpp.seniordrivers.org/index. cfm?selection=visionregs\&orderby=abbv\&sortorder=\&country= }\end{array}$ \\
\hline Illinois & $\begin{array}{l}\text { Foundation for Traffic Safety. Driver Licensing Policies and Practices. [Internet]. 2016. [cited September 2018]. } \\
\text { Available from: } \\
\text { http://lpp.seniordrivers.org/index.cfm?selection=visionregs\&orderby=abbv\&sortorder=\&country= }\end{array}$ \\
\hline I ndiana & $\begin{array}{l}\text { Foundation for Traffic Safety. Driver Licensing Policies and Practices. [Internet]. 2016. [cited September 2018]. } \\
\text { Available from: } \\
\text { http://lpp.seniordrivers.org/index.cfm?selection=visionregs\&orderby=abbv\&sortorder=\&country= }\end{array}$ \\
\hline
\end{tabular}

This article is protected by copyright. All rights reserved. 


\begin{tabular}{|c|c|}
\hline lowa & $\begin{array}{l}\text { va Department of Transport. Driver's License/ID. [Internet]. [no date]. [cited September 2018]. Available } \\
\mathrm{m} \text { https://iowadot.gov/mvd/driverslicense/fees-and-license-type }\end{array}$ \\
\hline Kansas & $\begin{array}{l}\text { undation for Traffic Safety. Driver Licensing Policies and Practices. [Internet]. 2016. [cited September 2018]. } \\
\text { ailable from: } \\
\text {-p://lpp.seniordrivers.org/index.cfm?selection=visionreas\&orderby=abbv\&sortorder=\&country= }\end{array}$ \\
\hline Kentucky & $\begin{array}{l}\text { undation for Traffic Safety. Driver Licensing Policies and Practices. [Internet]. 2016. [cited September 2018]. } \\
\text { tailable from: } \\
\text { tp://lpp.seniordrivers.org/index.cfm?selection=visionregs\&orderby=abbv\&sortorder=\&country= }\end{array}$ \\
\hline Louisiana & $\begin{array}{l}\text { Se Specialists of Louisiana. Louisiana Driver's License Vision Requirements. [Internet]. 2013. [cited September } \\
\text { 18]. Available from https://www.eyespecialistsofla.com/blog/bid/266260/louisiana-driver-s-license-vision- } \\
\text { quirements }\end{array}$ \\
\hline Maine & $\begin{array}{l}\text { reau of Motor Vehicles - State of Maine. Visual Disorders. [Internet]. [no date]. [cited September 2018]. } \\
\text { ailable from https://www. maine.gov/sos/bmv/licenses/VISUAL\%20DI SORDERS.pdf }\end{array}$ \\
\hline Maryland & $\begin{array}{l}\text { Maryland Department of Transportation. Motor Vehicle Administration - Vision Requirements. [Internet]. [no } \\
\text { date]. [cited September 2018]. Available from http://www.mva.maryland. gov/drivers/vision-requirements/ }\end{array}$ \\
\hline Massachusetts & $\begin{array}{l}\text { Foundation for Traffic Safety. Driver Licensing Policies and Practices. [Internet]. 2016. [cited September 2018]. } \\
\text { Available from: } \\
\text { http://lpp.seniordrivers.org/index.cfm?selection=visionreqs\&orderby=abbv\&sortorder=\&country= }\end{array}$ \\
\hline Michigan & $\begin{array}{l}\text { Department of State - Michigan. Visual Standards for Motor Vehicle Drivers' Licenses. [Internet]. [no date]. } \\
\text { [cited September 2018]. Available from https://www. michigan.gov/documents/Vision_Standards_19484_7.pdf }\end{array}$ \\
\hline Minnesota & $\begin{array}{l}\text { Foundation for Traffic Safety. Driver Licensing Policies and Practices. [Internet]. 2016. [cited September 2018]. } \\
\text { Available from: } \\
\text { http://lpp.seniordrivers.org/index.cfm?selection=visionreqs\&orderby=abbv\&sortorder=\&country= }\end{array}$ \\
\hline Mississippi & $\begin{array}{l}\text { Foundation for Traffic Safety. Driver Licensing Policies and Practices. [Internet]. 2016. [cited September 2018]. } \\
\text { Available from: }\end{array}$ \\
\hline
\end{tabular}

This article is protected by copyright. All rights reserved. 
http://lpp.seniordrivers.org/index.cfm?selection=visionregs\&orderby=abbv\&sortorder=\&country=

Missouri $\quad$ Foundation for Traffic Safety. Driver Licensing Policies and Practices. [Internet]. 2016. [cited September 2018]. Available from:

http://lpp.seniordrivers.org/index. cfm?selection=visionregs\&orderby=abbv\&sortorder=\&country=

Montana $\quad$ Foundation for Traffic Safety. Driver Licensing Policies and Practices. [Internet]. 2016. [cited September 2018]. Available from:

http://lpp.seniordrivers.org/index.cfm?selection=visionreqs\&orderby=abbv\&sortorder=\&country=

Nebraska Department of Motor Vehicles. Nebraska Department of Motor Vehicles - Chapter 7. [Internet]. [no date]. [cited September 2018]. Available from http://www.sos.ne.gov/rules-and-

regs/regsearch/Rules/Motor Vehicles Dept of/Title-247/Chapter-7.pdf

Nevada Department of Motor Vehicles - Official Website of the State of Nevada. [Internet]. 2018. [cited September 2018]. Available from http://www.dmvnv.com/dltesting.htm

New Foundation for Traffic Safety. Driver Licensing Policies and Practices. [Internet]. 2016. [cited September 2018].

Hamsphire Available from:

http://lpp.seniordrivers.org/index.cfm?selection=visionregs\&orderby=abbv\&sortorder=\&country=

New J ersey $\quad$ Foundation for Traffic Safety. Driver Licensing Policies and Practices. [Internet]. 2016. [cited September 2018]. Available from:

http://lpp.seniordrivers. org/index. cfm?selection=visionreas\&orderby=abbv\&sortorder=\&country=

New Mexico Foundation for Traffic Safety. Driver Licensing Policies and Practices. [Internet]. 2016. [cited September 2018]. Available from:

http://lpp.seniordrivers.org/index.cfm?selection=visionreas\&orderby=abbv\&sortorder=\&country=

New York Foundation for Traffic Safety. Driver Licensing Policies and Practices. [Internet]. 2016. [cited September 2018]. Available from:

http://lpp.seniordrivers.org/index. cfm?selection=visionregs\&orderby=abbv\&sortorder=\&country=

This article is protected by copyright. All rights reserved. 


\begin{tabular}{|c|c|}
\hline North Carolina & $\begin{array}{l}\text { North Carolina Society of Eye Physicians and Surgeons. Vision Requirements for Driving Safety. [Internet]. [no } \\
\text { date] [cited September 2018]. Available from http://www. nceyemd.org/pages/patient info.html }\end{array}$ \\
\hline North Dakota & $\begin{array}{l}\text { Foundation for Traffic Safety. Driver Licensing Policies and Practices. [Internet]. 2016. [cited September 2018]. } \\
\text { Available from: } \\
\text { http://lpp.seniordrivers.org/index.cfm?selection=visionreas\&orderby=abbv\&sortorder=\&country= }\end{array}$ \\
\hline Ohio & $\begin{array}{l}\text { Foundation for Traffic Safety. Driver Licensing Policies and Practices. [Internet]. 2016. [cited September 2018] } \\
\text { Available from: } \\
\text { http://lpp.seniordrivers.org/index.cfm?selection=visionreqs\&orderby=abbv\&sortorder=\&country= }\end{array}$ \\
\hline Oklahoma & $\begin{array}{l}\text { Foundation for Traffic Safety. Driver Licensing Policies and Practices. [Internet]. 2016. [cited September 2018] } \\
\text { Available from: } \\
\text { http://lpp.seniordrivers.org/index.cfm?selection=visionreas\&orderby=abbv\&sortorder=\&country= }\end{array}$ \\
\hline Oregon & $\begin{array}{l}\text { Foundation for Traffic Safety. Driver Licensing Policies and Practices. [Internet]. 2016. [cited September 2018] } \\
\text { Available from: } \\
\text { http://lpp.seniordrivers.org/index.cfm?selection=visionreas\&orderby=abbv\&sortorder=\&country= }\end{array}$ \\
\hline Pennsylvania & $\begin{array}{l}\text { Foundation for Traffic Safety. Driver Licensing Policies and Practices. [Internet]. 2016. [cited September 2018] } \\
\text { Available from: } \\
\text { http://lpp.seniordrivers.org/index.cfm?selection=visionreqs\&orderby=abbv\&sortorder=\&country= }\end{array}$ \\
\hline Rhode I sland & $\begin{array}{l}\text { Foundation for Traffic Safety. Driver Licensing Policies and Practices. [Internet]. 2016. [cited September 2018]. } \\
\text { Available from: } \\
\text { http://lpp.seniordrivers.org/index.cfm?selection=visionreqs\&orderby=abbv\&sortorder=\&country= }\end{array}$ \\
\hline South Carolina & $\begin{array}{l}\text { Foundation for Traffic Safety. Driver Licensing Policies and Practices. [Internet]. 2016. [cited September 2018]. } \\
\text { Available from: } \\
\text { http://lpp.seniordrivers.org/index.cfm?selection=visionreqs\&orderby=abbv\&sortorder=\&country= }\end{array}$ \\
\hline South Dakota & $\begin{array}{l}\text { Foundation for Traffic Safety. Driver Licensing Policies and Practices. [Internet]. 2016. [cited September 2018]. } \\
\text { Available from: }\end{array}$ \\
\hline
\end{tabular}

This article is protected by copyright. All rights reserved. 
http://lpp.seniordrivers.org/index.cfm?selection=visionreqs\&orderby=abbv\&sortorder=\&country=

Tennessee Foundation for Traffic Safety. Driver Licensing Policies and Practices. [Internet]. 2016. [cited September 2018]. Available from:

http://lpp.seniordrivers.org/index. cfm?selection=visionregs\&orderby=abbv\&sortorder=\&country=

Texas $\quad$ Foundation for Traffic Safety. Driver Licensing Policies and Practices. [Internet]. 2016. [cited September 2018]. Available from:

http://lpp.seniordrivers.org/index. cfm?selection=visionreqs\&orderby=abbv\&sortorder=\&country=

Utah Foundation for Traffic Safety. Driver Licensing Policies and Practices. [Internet]. 2016. [cited September 2018]. Available from:

http://lpp.seniordrivers.org/index. cfm?selection=visionregs\&orderby=abbv\&sortorder=\&country=

Vermont $\quad$ Foundation for Traffic Safety. Driver Licensing Policies and Practices. [Internet]. 2016. [cited September 2018]. Available from:

http://lpp.seniordrivers.org/index. cfm?selection=visionregs\&orderby=abbv\&sortorder=\&country=

Virginia $\quad$ Virginia Department of Motor Vehicles. DMV Visual Field Policy. [Internet]. 2017. [cited September 2018]. https://www.dmv.virginia.gov/drivers/\#medical/visualfield.asp

Washington Foundation for Traffic Safety. Driver Licensing Policies and Practices. [Internet]. 2016. [cited September 2018]. Available from:

http://lpp.seniordrivers.org/index.cfm?selection=visionregs\&orderby=abbv\&sortorder=\&country=

West Virginia Foundation for Traffic Safety. Driver Licensing Policies and Practices. [Internet]. 2016. [cited September 2018]. Available from:

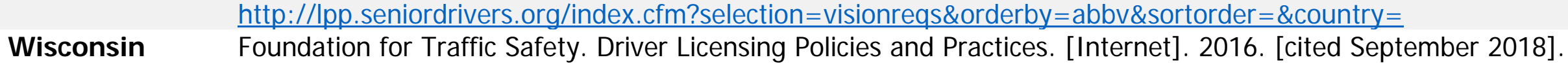
Available from:

This article is protected by copyright. All rights reserved. 


\section{http://lpp.seniordrivers.org/index.cfm?selection=visionreqs\&orderby=abbv\&sortorder=\&country=}

Wyoming Foundation for Traffic Safety. Driver Licensing Policies and Practices. [Internet]. 2016. [cited September 2018]. Available from:

http://lpp.seniordrivers.org/index.cfm?selection=visionregs\&orderby=abbv\&sortorder=\&country= 
Table 3: Search strategy by continent for visual field standard

\begin{tabular}{|c|c|}
\hline Continent Name & Details of Search \\
\hline \multirow[t]{4}{*}{$\begin{array}{l}\text { Australia and } \\
\text { Oceania }\end{array}$} & $\begin{array}{l}\text { Australia: Search performed. Results available and included in review. Individual states not searched } \\
\text { separately. }\end{array}$ \\
\hline & $\begin{array}{l}\text { New Zealand: Search performed. Results available and included in review. } \\
\text { Papua New Guinea: Search performed. Results available and included in review. }\end{array}$ \\
\hline & Fiji, Solomon I slands, Micronesia, Vanuatu: Search performed. No relevant results were found. \\
\hline & Samoa, Kiribati, Tonga, Marshall I slands, Palau, Tuvalu and Nauru: Not searched. \\
\hline Europe & $\begin{array}{l}\text { Search performed. Results available for European Union and included in review. Individual countries } \\
\text { were not searched separately. } \\
\text { United Kingdom: Search performed. Results available and included in review. }\end{array}$ \\
\hline Asia & $\begin{array}{l}\text { People's Republic of China: Search performed. Results available and included in review. } \\
\text { Hong Kong: Search performed. Results available and included in review } \\
\text { Taiwan: Search performed. Results available and included in review } \\
\text { Japan: Search performed. Results available and included in review } \\
\text { Singapore: Search performed. Results available and included in review } \\
\text { Malaysia: Search performed. Results available and included in review } \\
\text { Philippines: Search performed. Results available and included in review } \\
\text { India: Search performed. Results available and included in review }\end{array}$ \\
\hline
\end{tabular}

This article is protected by copyright. All rights reserved. 
Sri Lanka: Search performed. Results available and included in review

Indonesia, Thailand, South Korea, Afghanistan, Pakistan, Bangladesh, Vietnam: Search

performed. No relevant results were found.

Turkey, I ran, Myanmar, I raq, Saudi Arabia, Uzbekistan, Nepal, Yemen, North Korea, Kazakhstan, Syria, Cambodia, J ordon, Azerbaijan, United Arab Emirates, Tajikistan, I srael, Laos, Kyrgyzstan, Lebanon, Turkmenistan, State of Palestine, Oman, Kuwait, Georgia, Mongolia, Armenia, Qatar, Bahrain, Timor-Leste, Cyprus, Bhutan, Maldives, Brunei: : Not searched.

North America Search performed. Results available and included in review. Individual states searched.

South America Colombia: Search performed. Results available and included in review.

Brazil, Argentina, Peru, Venezuela, Chile, Ecuador, Bolivia, Paraguay, Uruguay, Guyana, Suriname: Search performed. No relevant results were found.

Africa Search performed using "Africa" combined with each of "driving", "minimum", "visual acuity", "visual field" and results were available for Kenya, Nigeria and South Africa. References of journal articles attained were also reviewed. Individual searches for each country was not performed.

Antarctica Search performed. No relevant results were found. 
Table 4: Summary of basic minimum visual standards world-wide for private driving licence

\begin{tabular}{ll}
\hline Jurisdiction & Visual Acuity Requirement \\
\hline COMMONWEALTH NATI ONS \\
\hline Australia & $\begin{array}{l}\text { A person is not fit to hold an unconditional licence if } \\
\text { the uncorrected VA }\end{array}$ \\
& eyes together is worse than $6 / 12$
\end{tabular}

\section{Visual Field Requirement}

Binocular visual field horizontal extent at least $110^{\circ}$ with $10^{\circ}$ above and below horizontal midline; or Cannot hold if any scotoma within a central radius of $20^{\circ}$ of the foveal fixation or other scotoma likely to impede driving performance

New Zealand Minimum combined VA of 6/12 - with or without Minimum standard is a binocular horizontal field of correcting lenses $140^{\circ}$ and should be no significant pathological field defect encroaching within $20^{\circ}$ of the point of fixation 
Papua New

Guinea

United Kingdom The minimum eyesight standard is a VA of at least $0.5(6 / 12)$ measured on the Snellen scale (with glasses or contact lenses, if necessary) using both eyes together or, if you have sight in one eye only, in that eye
The minimum standard vision required is that if one eye is less than $6 / 60$ vision or sightless-

(i) the other can be corrected by glasses to $6 / 12$; or

(ii) each eye can be corrected by glasses to $6 / 18$.

\section{Not Specified} defined as: 'A field of at least $120^{\circ}$ on the horizontal measured using a target equivalent to the white Goldmann III 4e settings. The extension should be at least $50^{\circ}$ left and right. In addition, there should be no significant defect in the binocular field which encroaches within $20^{\circ}$ of fixation above or below the horizontal meridian.'

If a visual field assessment is necessary to

determine fitness to drive, $\mathrm{DVLA}^{\ddagger}$ requires this to be a binocular Esterman visual field test

\section{EUROPE}

European Union Binocular VA, with corrective lenses if necessary, of at least $6 / 12$ when using both eyes together

ASIA

\section{People's}

Republic of
Naked vision or corrected vision of both eyes of that

of an applicant applying for a motor vehicle driver's
Horizontal visual field at least $120^{\circ}$; extension should be at least $50^{\circ}$ left and right; $20^{\circ}$ up and down No defects should be present within a radius of the central $20^{\circ}$ 


\begin{tabular}{|c|c|c|}
\hline China (PRC) & $\begin{array}{l}\text { license for other permitted types of vehicles shall be } \\
4.9 \text { or above in the logarithmic vision chart }\end{array}$ & \\
\hline Hong Kong & $\begin{array}{l}\text { Read motor vehicle registration mark at distance of } \\
23 \text { meters in good daylight - with or without } \\
\text { corrective lenses }\end{array}$ & Not Tested \\
\hline Taiwan & $\begin{array}{l}\text { On a bare eyesight examination, two eyes' eyesight } \\
\text { reaches over 0.6; each one reaches over } 0.5 \text {. Or, } \\
\text { after correction, two eyes' eyesight reaches over } \\
0.8 \text {; each one reaches over } 0.6\end{array}$ & Left and right eye can view a range of $150^{\circ}$ \\
\hline Japan & Binocular VA 20/30; or monocular VA 20/30 & $\begin{array}{l}\text { A minimum horizontal visual field of } 150^{\circ} \text { is required } \\
\text { on a modified Förster perimeter in monocular drivers }\end{array}$ \\
\hline Singapore & $\begin{array}{l}\text { At least } 6 / 12 \text { in one eye; if worse eye has VA less } \\
\text { than } 6 / 36 \text {, or if the person has monocular vision, his } \\
\text { horizontal field of vision should be tested }\end{array}$ & $\begin{array}{l}\text { Only tested if monocular VA less than } 6 / 36 \text { in the } \\
\text { worse eye is a horizontal field of at least } 120^{\circ} \\
\text { required }\end{array}$ \\
\hline Malaysia & $\begin{array}{l}\text { Minimum Snellen } 6 / 60 \text { in each eye without glasses; } \\
\text { Snellen } 6 / 12 \text { in the best eye with corrective glasses }\end{array}$ & Not Tested \\
\hline Philippines & $\begin{array}{l}\text { Distant binocular VA not less than } 20 / 40 \text { by Snellen } \\
\text { (or } 0.5,6 / 12 \text { ) in both eyes, with or without } \\
\text { corrective lenses }\end{array}$ & $\begin{array}{l}\text { Uninterrupted visual field of } 120^{\circ} \text { or better along the } \\
\text { horizontal meridian and } 20^{\circ} \text { or better, above and } \\
\text { below fixation, with both eyes open and examined } \\
\text { together }\end{array}$ \\
\hline India & VA $6 / 18$ or better & Not Tested \\
\hline Sri Lanka & $\begin{array}{l}\text { VA 6/12 in each eye with or without glasses; should } \\
\text { wear corrective lenses when driving }\end{array}$ & $\begin{array}{l}140^{\circ} \text { in the horizontal meridian. Defect in one eye } \\
\text { should be completely compensated by the other eye }\end{array}$ \\
\hline
\end{tabular}

This article is protected by copyright. All rights reserved. 
NORTH

\section{AMERICA}

United States of See Table 5

America

Canada

VA at least $20 / 50(6 / 15)$, with both eyes open \& examined together with or without aid of corrective lenses

\section{AFRI CA \\ South Africa}

According to the Snellen rating a minimum VA, with or without refractive correction, of $6 / 12$ (20/40) for each eye, or where the VA of one eye is less than $6 / 12(20 / 40)$ or where one eye of the person concerned is blind, a minimum VA for the other eye of $6 / 9(20 / 30)$

Kenya Not tested

Nigeria

At least 6/12 in the better eye and 6/36 in the poorer eye
Horizontal visual field of at least $120^{\circ}$ continuous along the horizontal meridian and at least $15^{\circ}$ continuous above and below fixation, with both eyes open and examined together

A minimum visual field of $70^{\circ}$ temporal, with or without refractive correction, in respect of each eye, or where the minimum visual field in respect of one eye is less than $70^{\circ}$ temporal, or where one eye is blind, a minimum total horizontal visual field of at least $115^{\circ}$ with or without refractive corrector

Not tested

Not tested

${ }^{\dagger}$ VA: Visual Acuity, ${ }^{\ddagger}$ DVLA: Driver and Vehicle Licensing Agency 
Table 5: Summary of basic minimum visual standards for private driving licence in the United States of America

\begin{tabular}{|c|c|c|}
\hline J urisdiction & Visual Acuity Requirement & Visual Field Requirement \\
\hline Alabama & Both eyes with/without correction 20/40 & $110^{\circ}$ horizontal, 80 vertical (binocular) \\
\hline Alaska & Both eyes with/without correction $20 / 40$ & None \\
\hline Arizona & Both eyes with/without correction 20/40 & $70^{\circ}$ temporal, $35^{\circ}$ nasal, monocular in at least one eye \\
\hline Arkansas & Both eyes with/without correction 20/40 & At least $140^{\circ}$ in two eyes, or at least $105^{\circ}$ in one eye \\
\hline California & Both eyes with/without correction 20/40 & None \\
\hline Colorado & Both eyes with/without correction 20/40 & $55^{\circ}$ temporal in both eyes and on eye at least $35^{\circ}$ nasal \\
\hline Connecticut & Both eyes with/without correction 20/40 & $\begin{array}{l}\text { A binocular field of } 140^{\circ} \text { in horizontal meridian, or } \\
\text { monocular field of } 100^{\circ} \text { in horizontal meridian }\end{array}$ \\
\hline Delaware & Both eyes with/without correction 20/40 & None \\
\hline District of Columbia & $\begin{array}{l}\text { No less than } 20 / 40 \text { in the best eye; or no less } \\
\text { than } 20 / 70 \text { in the best eye }\end{array}$ & Field of vision at least $140^{\circ}$ \\
\hline Florida & $\begin{array}{l}\text { Minimum of } 20 / 40 \text { vision in each eye with or } \\
\text { without correction is required, otherwise referral } \\
\text { to ophthalmologist for further assessment }\end{array}$ & $130^{\circ}$ horizontal binocular \\
\hline Georgia & $\begin{array}{l}20 / 60 \text { or better, corrected or uncorrected in at } \\
\text { least one eye }\end{array}$ & $\begin{array}{l}140^{\circ} \text { with both eyes open; monocular drivers minimum } \\
\text { of } 70^{\circ} \text { temporal } 50^{\circ} \text { nasal }\end{array}$ \\
\hline Hawaii & Both eyes with/without correction 20/40 & $140^{\circ}$ binocular, $70^{\circ}$ monocular \\
\hline Idaho & Both eyes with/without correction 20/40 & None \\
\hline Illinois & Both eyes with/without correction 20/40 & $140^{\circ}$ binocular; $105^{\circ}$ monocular $\left(70^{\circ}\right.$ temporal, $35^{\circ}$ \\
\hline
\end{tabular}

This article is protected by copyright. All rights reserved. 
Indiana

\section{Iowa}

Kansas

Kentucky

Louisiana

Maine

Maryland

Massachusetts

Michigan

Minnesota

Mississippi

Missouri

Montana

Nebraska

Nevada

New Hamsphire

New Jersey

New Mexico

New York
$20 / 40$ in the better eye with or without correction

$20 / 40$ in one or both eyes

Both eyes with/without correction 20/40

At least $20 / 60$ or better in at least one eye

At least 20/40 in the dominant eye

Both eyes with/without correction 20/40

At least $20 / 40$ in each eye

Both eyes with/without correction 20/40

Both eyes with/without correction 20/40

Both eyes with/without correction 20/40

Both eyes with/without correction 20/40

Both eyes with/without correction 20/40

Both eyes with/without correction 20/40

Both eyes with/without correction 20/40

Both eyes with/without correction 20/40

$20 / 40$ (20/30 if one eye)

Both eyes with/without correction 20/50

$20 / 40$ or better in at least one eye, with or without glasses

Both eyes with/without correction 20/40 nasal)

$120^{\circ}$ binocular; $70^{\circ}$ monocular

$140^{\circ}$ binocular

$110^{\circ}$ binocular; $55^{\circ}$ monocular

Horizontal field of vision at least $35^{\circ}$ to the left and right of fixation and vertical field of vision at least $25^{\circ}$ above and below fixation

None

A minimum visual field of $120^{\circ}$ horizontal with minimum of $50^{\circ}$ to left and $50^{\circ}$ to right of fixation A continuous field of $140^{\circ}$ binocular A $120^{\circ}$ minimum in the horizontal field $140^{\circ}$ minimum binocular $105^{\circ}$ minimum binocular $150^{\circ}$ binocular; $70^{\circ}$ temporal $35^{\circ}$ nasal monocular $55^{\circ}$ or better in both eyes; or $85^{\circ}$ in a monocular driver None; Only for commercial drivers $140^{\circ}$ or greater

None

None

None

A visual field of $120^{\circ}$ in the horizontal meridian, with at least $30^{\circ}$ in the nasal field of one eye $140^{\circ}$ binocular field of vision 
North Carolina

Both eyes with/without correction 20/40

North Dakota

Both eyes with/without correction 20/40

Ohio

Oklahoma

Oregon

Pennsylvania

Rhode Island

South Carolina

South Dakota

Tennessee

Texas

Utah

Vermont
Both eyes with/without correction 20/40 or better

$20 / 60$ or better with/without correction, or $20 / 50$ or better in one eye

VA of $20 / 70$ or better when looking through both eyes

Both eyes with/without correction 20/40

Both eyes with/without correction 20/40

Each eye by itself most score 20/40 or better with or without glasses

Both eyes with/without correction 20/40

Both eyes with/without correction 20/40

Without corrective lenses, 20/40 or better each eye and both together; with corrective lenses, $20 / 50$ or better with best eye or both together Both eyes with/without correction 20/40

Both eyes with/without correction 20/40
A visual field of $60^{\circ}$ in one eye, or $30^{\circ}$ on each side of the central point of fixation

Horizontal visual field of $105^{\circ}$ degrees or better, binocular or monocular

Minimum $70^{\circ}$ temporal in each eye

At least $70^{\circ}$ horizontal meridian in one eye alone or with both eyes

A field of vision at least $110^{\circ}$ binocular or monocular

A combined field of vision at least $120^{\circ}$ in the horizontal meridian

A minimum of $115^{\circ}$ in the horizontal meridians in binocular drivers; minimum of $40^{\circ}$ nasally and

$75^{\circ}$ temporally in monocular drivers

Field of vision of at least $70^{\circ}$ in the horizontal meridian in each eye

None

For professional drivers only

None

A minimum of $120^{\circ}$ in horizontal meridian; with $60^{\circ}$ to both right and left)

Both eyes, $60^{\circ}$ or more external each eye; One eye, 
Virginia

Washington

West Virginia

Wisconsin

Wyoming
Both eyes with/without correction 20/40

Both eyes with/without correction 20/40

Both eyes with/without correction 20/40

Both eyes with/without correction 20/40

Both eyes with/without correction 20/40 $60^{\circ}$ or more external, 60 or more nasal.

$110^{\circ}$ or better, horizontal vision in one or both eyes $110^{\circ}$ in the horizontal meridian

None

A minimum of $70^{\circ}$ field of vision

A total combined horizontal field of vision with both eyes at least $120^{\circ}$ 
Table 6: Summary of basic minimum visual standards world-wide for commercial driving licence

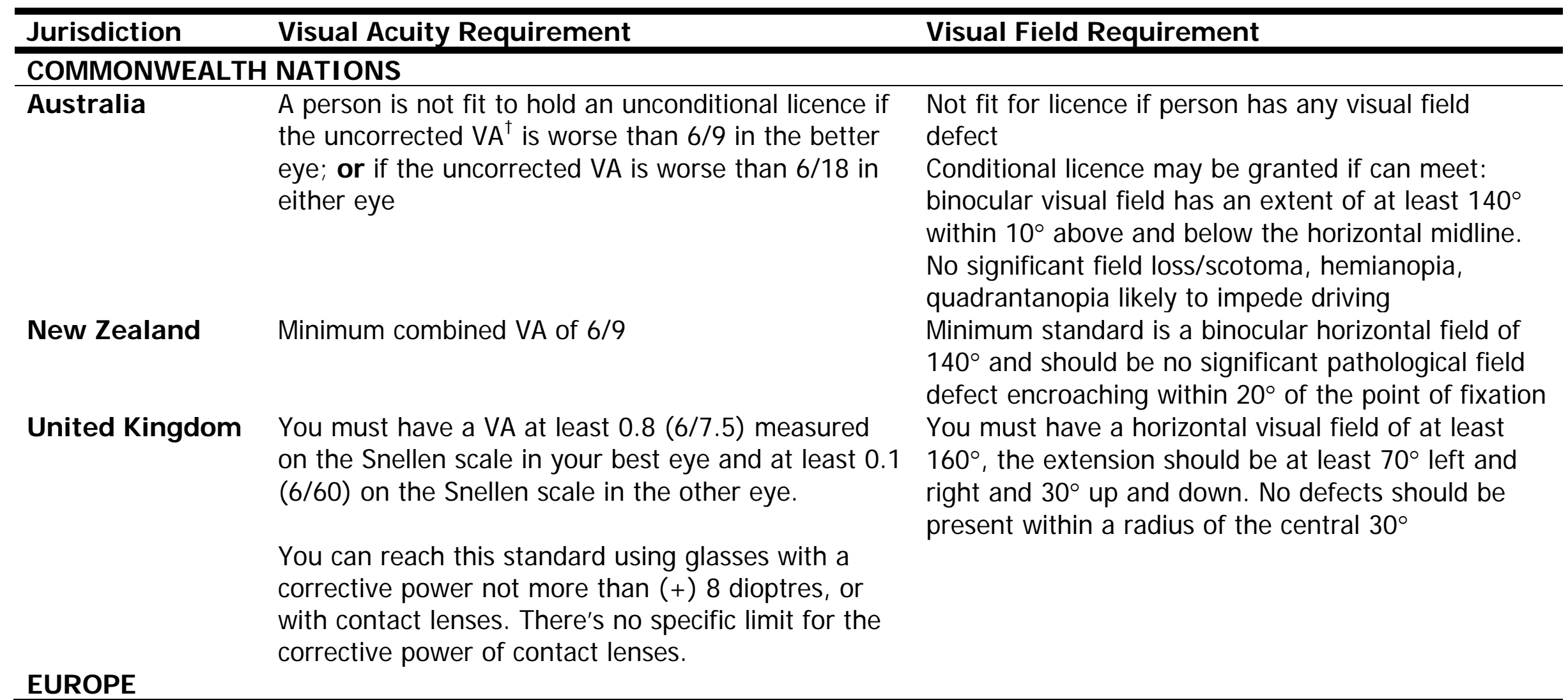

This article is protected by copyright. All rights reserved. 
European Union VA, with corrective lenses if necessary, of at least 0.8 in the better eye and at least 0.1 in the worse eye. If corrective lenses are used to attain the values of 0.8 and 0.1 , the minimum VA ( 0.8 and 0.1$)$ must be achieved either by correction by means of glasses with a power not exceeding plus eight dioptres, or with the aid of contact lenses. The correction must be well tolerated

\section{ASI A}

\section{People's \\ Republic of \\ China (PRC)}

The naked vision or corrected vision of both eyes of

Not tested

an applicant applying for a motor vehicle driver's

license for large passenger buses, towing vehicles, urban buses, medium-sized passenger buses, large trucks, trolley buses or trams shall be 5.0 or above in the logarithmic vision chart

\section{Hong Kong \\ Singapore \\ Malaysia}

Ability to read motor vehicle registration mark at distance of $23 \mathrm{~m}$ in good daylight (with aid of spectacles or other corrective lenses, if worn) Should have VA at least $6 / 12$ in each eye VA of at least $6 / 12$ in each eye with or without corrective aids such as glasses or contact lenses

India $\quad 6 / 18$ or better

Moreover, the horizontal visual field with both eyes should be at least $160^{\circ}$, the extension should be at least $70^{\circ}$ left and right and $30^{\circ}$ up and down. No defects should be present within a radius of the central $30^{\circ}$
Not tested

Not tested

A binocular visual field at least $120^{\circ}$ along the horizontal meridian and $20^{\circ}$ above and below the horizontal midline

Not tested 


\begin{tabular}{|c|c|c|}
\hline $\begin{array}{l}\text { NORTH } \\
\text { AMERICA }\end{array}$ & $\begin{array}{l}6 / 9,6 / 12 \text { or vice versa with or without glasses; } \\
\text { should wear corrective lenses when driving; An } \\
\text { uncorrected minimum vision in the worse eye - } 6 / 60\end{array}$ & $\begin{array}{l}140^{\circ} \text { in the horizontal meridian; no defect within } 20^{\circ} \\
\text { from fixation horizontally or vertically }\end{array}$ \\
\hline $\begin{array}{l}\text { United States of } \\
\text { America }\end{array}$ & $\begin{array}{l}\text { VA at least 20/40 in each eye with or without } \\
\text { correction. The use of corrective lenses should be } \\
\text { noted on the Medical Examiner's Certificate. }\end{array}$ & $\begin{array}{l}\text { At least } 70^{\circ} \text { field of vision in horizontal meridian } \\
\text { measured in each eye }\end{array}$ \\
\hline Canada & $\begin{array}{l}\text { At least } 20 / 30(6 / 9) \text { with both eyes open and } \\
\text { examined together and not poorer than } 20 / 400 \text { in } \\
\text { the weaker eye, with or without aid of corrective } \\
\text { lenses }\end{array}$ & $\begin{array}{l}\text { Horizontal visual field of at least } 150^{\circ} \text { continuously } \\
\text { along the horizontal meridian and at least } 20^{\circ} \\
\text { continuously above and below fixation, with both } \\
\text { eyes open and examined together }\end{array}$ \\
\hline \multicolumn{3}{|r|}{ 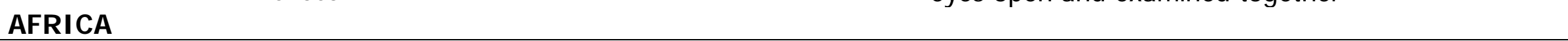 } \\
\hline South Africa & $\begin{array}{l}\text { According to the Snellen rating a minimum VA, with } \\
\text { or without refractive correction, of } 6 / 9(20 / 30) \text { for } \\
\text { each eye; }\end{array}$ & $\begin{array}{l}\text { A minimum visual field of } 70^{\circ} \text { temporal in respect of } \\
\text { each eye, with or without refractive correction }\end{array}$ \\
\hline Kenya & At least $6 / 9$ in best eye; at least $6 / 60$ in other eye & $\begin{array}{l}\text { Normal visual fields } \\
\text { Using standard methods, but at least by } \\
\text { confrontation method }\end{array}$ \\
\hline Nigeria & $\begin{array}{l}\text { At least } 6 / 9 \text { in better eye and } 6 / 24 \text { in the poorer eye } \\
\text { with or without glasses }\end{array}$ & $\begin{array}{l}\text { Optec } 1000 \text { test (free and mandatory for commercial } \\
\text { drivers) }\end{array}$ \\
\hline
\end{tabular}




\section{University Library}

\section{- M M N E R VA A gateway to Melbourne's research publications}

Minerva Access is the Institutional Repository of The University of Melbourne

Author/s:

Yan, MK;Kumar, H;Kerr, N;Medeiros, FA;Sandhu, SS;Crowston, J;Kong, YXG

Title:

Transnational review of visual standards for driving: How Australia compares with the rest of the world

Date:

2019-07-03

\section{Citation:}

Yan, M. K., Kumar, H., Kerr, N., Medeiros, F. A., Sandhu, S. S., Crowston, J. \& Kong, Y. X. G. (2019). Transnational review of visual standards for driving: How Australia compares with the rest of the world. CLINICAL AND EXPERIMENTAL OPHTHALMOLOGY, 47 (7), pp.847-863. https://doi.org/10.1111/ceo.13572.

Persistent Link:

http://hdl.handle.net/11343/286114 